\title{
Progress of research on transportation geography in China
}

\author{
JIN Fengjun ${ }^{1}$, WANG Chengjin ${ }^{1}$, CAO Youhui ${ }^{2}$, CAO Xiaoshu ${ }^{3}$, WANG Jiaoe ${ }^{1}$, \\ DAI Teqi ${ }^{4}$, JIAO Jingjuan ${ }^{1,5}$ \\ 1. Key Laboratory of Regional Sustainable Development Modeling, Institute of Geographic Sciences and \\ Natural Resources Research, CAS, Beijing 100101, China; \\ 2. Nanjing Institute of Geography and Limnology, CAS, Nanjing 210008, China; \\ 3. School of Geography and Planning, Sun Yat-sen University, Guangzhou 510275, China; \\ 4. School of Geography, Beijing Normal University, Beijing 100875, China; \\ 5. University of Chinese Academy of Sciences, Beijing 100049, China
}

\begin{abstract}
As an important branch of human geography, transportation geography has experienced three periods of evolution: foundation, systematization, and rapid development of the discipline. It has gradually become a relatively mature discipline. During the period 19301980 , the development of transportation geography consisted mainly of the publication of theoretical texts. During 1980-2000, it gradually became a systematic discipline. Since the start of the 21 st century, transportation geography has focused mainly on exploring the impacts of transportation on socio-economic development. Currently, studies on transportation geography have led to significant developments in a number of areas, including transportation theory, facility distribution and planning, transportation flows and network analysis, evaluation of transport modes, transportation planning, and simulation and assessment of urban transportation. Such studies have also enriched human geography research, provided a wider geographical overview and elucidated the development mechanism of transportation, as well as helped to understand the impacts of transport development on socio-economic systems. Some findings obtained by geographers have been widely used in transportation geography and related fields, including the four basic laws of transportation generation, the hub-spoke mode of transport organization, the subordinating and guiding functions of transportation on socio-economic development, regional transport dominance measures, accessibility measures, and spatial organization of port systems.
\end{abstract}

Keywords: transportation geography; evolutionary process; research field; academic contribution; development trend

\section{Introduction}

With the rapid development of transport networks throughout the world, transportation ge-

Received: 2016-04-15 Accepted: 2016-05-06

Foundation: National Natural Science Foundation of China, No.41171107; No.41371143

Author: Jin Fengjun (1961-), Professor, specialized in transport geography and regional development studies. E-mail: jinfj@igsnrr.ac.cn 
ography has become a discipline with its own theoretical and practical framework. It is a branch of geography that is concerned mainly with describing, explaining, and predicting flows of people, goods, and information on the Earth's surface (Giuliano, 2001). However, the key aspects of transportation geography are quite different in different regions and different periods. Transportation geography in the US during the 1950s focused mainly on spatial, quantitative, and theoretical studies, but since the 1970s it has been concentrating on quantitative studies together with the development of a complex interweaving of philosophical and definitional paradigms (Taaffe and Gauthier, 1994). Transport research in Europe has also tended to focus on quantitative work, principally the exploration of cost-benefit ratios and the impact of transport networks on accessibility, mobility, and socio-economic development (Hall, 2010). In a move toward the European approach, transport research in Israel is also becoming increasingly quantitatively oriented, and is acquiring more importance in the fields of planning and policy making (Givoni, 2015). However, transportation geography in Russia and Japan is still treated as an important branch of economic geography. Although Russia owns the developed modern transport network, the studies on transport geography are rare in the international journals, especially before 1989 . There were two new trends of transport research in Russia after 1989: humanization and quantification (Wu et al., 2009). The transport research in Japan is closely related to the socio-economic development. Before the 1990s, the studies mainly concentrated on exploring the impacts of high-speed rail, expressway and aviation network on accessibility and economic development (Okada, 1994). Now studies have changed to concentrate on urban automobile transport and regional public transport, and their impacts on regional structure and economic development (Koichi, 2014). As a developing country, Peru has focused mainly on urban mobility issues, on the link between rural development and accessibility, and on broader trans-boundary connections (Keeling, 2015).

Review on the transportation geography of China has not featured in the international literature, although since the 1990s there has been significant growth in the number of articles on transport issues published within China, especially since the high-speed rail (HSR) network was put into operation in 2003. As the third largest country by area in the world, the first by population, and the second by GDP, China is influenced significantly by its transportation. In the past 100 years, transportation in China has experienced rapid development, leading to it becoming the country with the largest HSR network and the second largest expressway network in the world. The transportation system in China is a comprehensive network involving modes of air, railway, highway, marine and river transport, with the consequence that transport research in China has a wide and complex scope. Therefore, a summary of transportation geography research in China is a significant task that is likely to provide useful suggestions to researchers in this field. The main aim of this paper is thus to offer a brief evaluation of transportation geography research and publications in China and to make proposals for future research.

\section{Development of transportation geography}

The development of transportation geography in China can be dated back to 1931, when Sheng (1931) translated and edited the first systematic book on the subject, which introduced the theory of transportation geography and sectorial transportation geography, and 
described the distribution of transport networks throughout the world, especially in China. However, at that time, transportation geography was regarded as just one area of economic geography, albeit an important one, and did not become an independent discipline until the 1950s. Since then, its evolution can be divided into three stages: the foundation of the discipline, followed by its systematization, and then its subsequent rapid development.

\subsection{Foundation of the discipline (1950s-1970s)}

During this period, transport research in China was mainly included in the field of economic geography. In 1957, the book Chinese Geography: Economic Geography, edited by researchers at the Chinese Academy of Sciences (CAS), was published, which systematically summarized the statistical characteristics and distribution of transport in the major regions of China. Zhang (1965) analyzed the conditions, characteristics, configuration, and freight flow of the transport industry in China in his book Introduction to Chinese Economic Geography: Transportation Geography. Meanwhile, empirical research in transportation geography focused mainly on analyzing the natural environment of the regions alongside transport routes, the characteristics of passengers and freight, the distribution of transport networks, and the relationship between transport and economic activities from the perspective of economic geography (Shen, 1952; Wu et al., 1955; Huang, 1957). The aims of these studies were to provide suggestions to central and local governments with regard to the location of transport routes. On the basis of empirical research, Yang (1964) proposed a natural regionalization of the transport network, dividing the mainland of China into seven regions and 33 subregions according to the natural conditions relevant to highway construction. Geng et al. (1978) enriched this natural regionalization of transport network by considering both a dominant factor and multiple factors.

\subsection{Systematization of the discipline (1980-2000)}

Transportation geography in China experienced rapid development during the period 1980-2000. The theory of transportation geography was formed into a systematic discipline, with several books being published on the topic. Transportation Geography, edited by Yang et al. (1986), was the most important theoretical work and had a great influence on the development of transportation geography in China. This book presented a systematic summary of the theoretical and practical experience of transport development in China and introduced the basic theories of transportation geography and sectorial transportation geography from the perspectives of the nature of the discipline, transport planning, network layout, and flow patterns. On the basis of this book, Zhang et al. (1993) proposed a theoretical framework for spatial transportation linkage and traffic economic belts in Spatial Transportation Linkage: Theoretical Study, Experimental Analysis and Forecasting Methods, while Zhang et al. (2000) described experimental research on transport networks in China in Traffic Economic Belts. Books were also published specifically introducing the development, layout, spatial evolution, and mechanism of transportation in China (Wang and Cai, 1986; Chen et al., 1993, 2000; Zhang, 1993). Along with its theoretical development, transportation geography became the main subject of a number of courses and fields of study in some institutes and universities. In 1983, the first research group on transportation geography in China was established in the Department of Industry and Transportation Geography at the Institute of Geo- 
graphic Sciences and Natural Resources Research (IGSNRR) of the CAS. Researchers in this group focused mainly on studying the theory of transportation geography, the spatial patterns of transportation and logistics, and the relationship of these to socio-economic development throughout the world, but especially in China. Courses devoted mainly to transportation geography and to urban transportation geography were also set up in some universities.

With the support of the National Natural Science Foundation of China and other foundations, various researchers carried out a large number of specialized studies of traffic theory and practice, which helped to improve the depth and quality of transportation geography research. Empirical research focused mainly on the spatial distribution of ports $(\mathrm{Xu}, 1990$; Cao, 1999) and railways (Ye, 1998) and on the impact of transportation on regional development (Rong, 1995). During this period, a number of researchers put the theoretical tools and evaluation methods of transportation geography into practice in the context of regional transportation planning, natural regionalization of traffic infrastructure, the development and layout of coastal ports, and the construction of infrastructure along with territorial development.

\subsection{Rapid development of the discipline (2000 onwards)}

Since 2000, transportation geography in China has entered into a period of rapid development. The transportation system in China has become an integrated network, including railway, highway, marine, river, and air transport. Influenced by the rapid development of the economy, there is an increasing demand for high-level and high-speed transport. The development of transportation in this period has focused on spatial optimization and reconstruction of the transport network. Experimental research has focused mainly on studying the impacts of railway electrification, expansion of expressways and high-speed rail, airline reorganization, and the integrated transport network on accessibility, mobility, regional development, and regional structure (Jin and Wang, 2004; Wang et al., 2009b; Cao et al., 2004). The research group at the IGSNRR, CAS is still the largest contributor to the literature, with four books being published so far during this period. These books have concentrated on introducing the development, layout, evolution, and mechanism of the transport infrastructure (Jin, 2012), the container network (Wang, 2012), logistical enterprises (Wang, 2014), and the aviation network (Mo and Wang, 2012), both worldwide and in China. Another representative work is the book Spatial Evolution of the Guangzhou-Shenzhen-Hong Kong Transport Corridor, by Cao and Yan (2006), which explores the impact of transport construction on regional structure. Meanwhile, researchers have begun to explore the formation, evolution, and spatial complexity of logistics, passenger flow, information flow, and capital flow from the perspective of transport organization and spatial flow theory. Attempts have also been made to identify universal scientific parameters in the evaluation of models of transportation geography and to explore general spatial interactions in the nature-human system, which could provide a scientific foundation for regional, metropolitan, ecological, and urban planning. An increasing number of researchers are paying greater attention to the human and environmental impacts of transport infrastructure and are exploring the mechanisms of interaction among transportation, urbanization, and regional socio-economic development, by considering ecological, social, and economic effects. 
Overall, the nature of transport research has changed from description of phenomena to summarization of rules, from factor analysis to mechanism exploration, from evaluation of layouts to analysis of evolution processes, from quantitative analysis to qualitative elaboration, and from single-factor analysis to comprehensive factor analysis. A number of new theories and mathematical models focusing on Chinese transportation characteristics have also been proposed. In terms of its results, transportation geography in China has become an important branch of human geography, with independent research objectives, theories, and methods, and has the potential to provide an important theoretical basis for understanding spatial and human activities.

\section{Current research focuses}

With the development of transportation geography in China, studies focus mainly on the following aspects: accessibility, spatial organization of transport, coordination of transportation itself and with the others, and specific research with a particular perspective on the geographical problems faced by transportation in China.

\subsection{Accessibility}

The development of expressway, civil aviation, container transport, HSR, and urban rail transit networks has large influence on regional location, resource allocation, and spatial interaction. Using spatial analysis and other methods of transportation geography, researchers have explored the impacts on accessibility and regional structure of highways (Cao et al., 2005; Wang et al., 2015; Liu et al., 2009), railways (Jin and Wang., 2004; Wang and Jin, 2005; Wu et al., 2009), expressways (Wang et al., 2011), HSR lines (Jiao et al., 2014), aviation networks (Jin, 2001; Xue, 2008; Zhou and Hu, 2002; Wu et al., 2006), and integrated transport networks (Jiang et al., 2010) at national, regional, and city levels from the perspectives of cost-space convergence, time-space convergence, and composite cost. They have found that the expansion or upgrading of land transport networks (highway and railway) has greatly enhanced the core-periphery structure and corridor effects, with the accessibility of core cities and cities located along trunk transport lines being greatly improved, while the city hierarchy evaluated in terms of the aviation network presents a triangular balance pattern, with Beijing, Shanghai, and Guangzhou as its centers (Wang et al., 2006).

\subsection{Spatial organization of transport networks}

Spatial organization of transport networks is one of the key objects of study in transportation geography. It is significant for the analysis of the regional structure, evolution, and mechanism of transport networks. Since the mid-1990s, researchers have achieved some progress in their understanding of the expansion and organization of transport networks. Most studies have focused on the physical and organizational networks of transportation systems, both of which reflect the supply characteristics of transportation. Using methods from graph theory and spatial analysis, researchers have explored the development, formation, spatial patterns, and organization of physical transportation networks, including railway (Wang et al., 2009a), expressway (Zhang, 2007), highway (Wang et al., 2014), and HSR networks (Jiao et al., 2015). Studies of organizational networks have focused mainly on the mechanisms, influ- 
encing factors and evolution rules of aviation flow, railway passenger flow, and highway traffic flow, using methods from complex network theory and spatial interaction theory. Studies on the spatial organization of transportation have led to greater understanding of the evolution, formation mechanism, spatial distribution of transport networks as well as methods for evaluating it.

\subsection{Coordination of transportation}

In early studies, research in this area focused mainly on the relationship between transportation and natural conditions. Influenced by improvements in transport technology, transportation has come to play an increasingly significant role in economic development. Coordination within the transportation system and between transportation and other systems has become of great importance. Studies on the coordination within the transportation system have focused mainly on exploring the mechanisms of cooperation and competition of different transport modes and the connections among different parts of the integrated transport network at national, regional, and city levels. For example, Wang et al. (2015) investigated the competition between HSR and air transport in China from a geographical perspective. Studies on the coordination between transportation and other systems have concentrated mainly on examining relationships between transport network on the one hand and urban hierarchy (Jin, 2001), economic development (Wang and Zhang, 2010), and regional structure (especially in urban agglomerations) (Zhang et al., 2011) on the other. On the basis of functions and effects, relationships between transportation and economic development can be divided into three types: advanced transportation, coordinated transportation and economic development, and lagged transportation (Jin, 2004, 2013). An unbalanced relationship between transportation and economic development would generate growth poles, traffic corridors, and regions of spatial agglomeration.

\subsection{Unique perspectives of research on transport in China}

As well as seeking general rules, transportation geography in China also focuses on exploring the unique geographical problems encountered by transportation in this country, influenced by spatial variations in natural conditions, human-land conflicts, and constraints imposed by resources and environment. Research on the unique geographical problems focuses mainly on the following five aspects. (1) The first of these is concerned with the formation and basic layout of transportation geography in China. Chen et al. (1993, 2000) and Wang and Cai (1986) systematically summarized the formation and characteristics of transportation geography in China from the perspectives of the conditions of development, evolution, and specific properties of different transport modes, as well as spatial patterns of transport networks. (2) The second aspect concerns the relationship between transportation and territorial development. China is a typical country with a large population and a small amount of land per capita and with great pressures on resources and environment. Land, energy, and environment are the three main constraints on regional development in China, and also have effects on the construction of transportation. Transport geographers in China have examined the relationship between transportation and territorial development from both theoretical and practical perspectives by exploring the formation of traffic economic belts. (3) The third aspect involves studies on the energy transport system. The construction of an energy trans- 
port system is of great importance for China. Given the unbalanced spatial distribution of energy resources, a system is required to transport energy from producing areas to markets. The coordinated development of coal exploitation and energy transportation is of vital importance to China and also a hot spot for transport researchers. (4) The fourth area of study concerns the status of China's transport network in the world. Recently, researchers in China have begun to explore the characteristics of transportation in the other countries with regard to their possible application to Chinese conditions. (5) Transport researchers have also taken an active part in regional and metropolitan planning, and in major function-oriented zoning and urban system planning, which play an important role in territorial development in China.

\section{Academic contributions}

\subsection{Basic laws of spatial interaction by transportation}

Spatial interaction is a common phenomenon in natural and socio-economic systems. Spatial flows, including those of material, energy, information, capital, and passengers, are the basic components of spatial interaction. A transport network involving passenger and freight flow is also a basic expression of spatial interaction. From an exploration of transport flow in China, Zhang et al. (1993) proposed a transport linkage theory, which thought that the evolution of spatial interaction obeyed four general rules: generation, growth, distribution, and communication. The theory could largely explain the evolution of spatial linkages, especially that through the transport network. They also proposed a number of methods to evaluate the structure, mode, and mechanism of spatial interactions. As an original theory based on Chinese characteristics, transport linkage theory has considerably enriched the theoretical foundations of transportation geography. Some researchers have found this theory useful for analyzing real geographical phenomena by exploring the rules of evolution of passenger flow and freight flow in China (Zhang et al., 1994a, b; Xiu et al., 2008).

\subsection{The concept of transport dominance and methods for its evaluation}

Transport infrastructure plays an important role in shaping the configuration of the spatial structure of a socio-economic system through its effect on the mechanism of agglomeration and diffusion of economic activities. Transport dominance has been proposed as a method of evaluating the agglomeration and diffusion of economic activities (Jin et al., 2008). It has been used to measure the development level of transport networks in a region and to reflect their capacity to support regional socio-economic activities (Jin et al., 2010). Jin et al. (2008) measured transport dominance with regard to three aspects: quality, quantity, and advantage, measured by density, proximity, and accessibility indices using the spatial analysis tools in ArcGIS software, which could be evaluated from both separated and integrated transport network. This index of transport dominance is a ratio, i.e., it is evaluated in comparison with a larger system or with reference to adjacent or target areas (Jin et al., 2010). That is to say, the transport dominance of a province or a city is calculated based on the whole country system or a regional system.

\subsection{Evolution of spatial cascade system}

Influenced by the rapid development of informatization and expansion of transport network, 
studies on the efficiency of spatial organization and construction of transport network are becoming a new hot topic in transportation geography. Jin (2013) proposed a spatial cascade system, defining it in terms of four aspects, namely, cost-space convergence, time-space convergence, cost convergence-flow expansion, and space coupling and coordination, which could be used to explain the spatial distribution, organization, and evolution of socio-economic phenomena. In a spatial cascade system, socio-economic elements tend to form a spatial system with a clear hierarchy, close relationships, and a balanced and steady state by changing the interaction mechanism between hubs and nodes in the network. The geographical phenomenon of a spatial cascade system can be found in the evolution of freight flows on railways, passenger flows on airlines, container transport, and other spatial organizations of socio-economic activities (Jin et al., 2004; Jin, 2013). A hub-spoke system is a typical case of a spatial cascade system. Jin and Wang (2005) analyzed the development of an international hub-spoke system in the context of the organization of air transport, current problems, and the development of China in the international environment. The concept of a hub-spoke system can also be applied to maritime transport systems, telecommunication systems, postal services, and rail systems, among others (Wu et al., 2010).

\subsection{Port systems and their evolution}

Since the 1980s, studies in transportation geography have achieved great progress with regard to the evolution and spatial organization of port systems and container transport networks and port-city interactions. The theory of port geography has been greatly enriched. $\mathrm{Wu}$ and Gao (1989) divided port-city evolution into three stages, the primary commercial economy, the port-industrial economy, and the multiple economy, according to different combinations of port-city direct linkage, indirect linkage, and self-growth. Wang (2007) analyzed the evolution of a port system over a long period and found that the driving forces influencing its evolution included the economic development and allocation of industry, spatial interactions between the political central district and the economic central district, international trade, foreign competition, and cooperation and competition with other modes of transport. These findings were in contrast to those of traditional studies of port systems, which exaggerated the role of foreign competition. Han et al. (2008) proposed a mode of organization of container transportation, involving hub ports, transfer ports, and a transport corridor, which shared a great number of features with that proposed by Notteboom (Wang, 2014). Cao et al. (2003) proposed a four-phase model that illustrated the dynamic developmental process of coastal container port systems and found that government regulation and enterprise investment were the important influencing factors. Wang (2008) proposed a recognition model of hub ports and explored the hub-spoke structure of coastal container port systems. Hinterland is the basis for the development and existence of ports. As an overlapping hinterland is shared by a number of ports, it is important to establish an appropriate combination of ports. Chen $(1984,1991$, and 1996) defined a spatial combination of ports by combining hub ports, a major port, a transfer port, an industrial port, and a local port to explore the interactive relationship among ports, transportation, industry, and cities.

\subsection{Technical and economic evaluation of airport distribution in China}

Air transport, especially passenger transport, has become an important mode for regional 
communication and plays an important role in socio-economic development, influenced by economic globalization and regional economic integration. Studies of air transport focus mainly on the following two aspects. (1) The first is the efficient evaluation of the spatial distribution of airports and its spatial optimization (Dai et al., 2014). Researchers have defined technical and economic criteria for airport distribution, considering time cost between cities, service hinterland, accessibility, and economic development of the service hinterland, which is significant for the location choice and the construction scale of airports. (Wang et al., 2006; Wang and Mo, 2009). (2) The second aspect concerns the spatial pattern and organization of the airline network. Researchers have explored the structure of airline networks and air passenger networks using evaluation indicators from complex network theory and geographic information systems (GIS), and have found that airline networks have the characteristics of small-world networks and follow a scale-free distribution (Wang et al., 2011, 2014).

\subsection{Geographic impacts of high-speed transport}

With the rapid development of air transport, HSR, and expressways in China, high-speed transport is causing changes in regional structure, population mobility, geographical division of labor, and regional linkages. Researchers have examined the impact of high-speed transport on accessibility, regional development, regional structure, and interaction among cities at national, regional, and city levels. According to the results and conclusions of empirical research, the impacts of high-speed transport can be summarized into four types: time-space convergence, agglomeration and diffusion effects, spatial reconstruction, and axial reinforcement effects. The development of HSR and expressways generate uneven time-space convergence and corridor effects and increase the disparities between core and peripheral cities (Jiao et al., 2014; Wang et al., 2011). The evolution of the HSR network has enhanced the hierarchy of cities as measured by passenger train data (Jiao et al., 2016). Similar results have been found from studies of air passenger transport (Jin et al., 2004; Wang and Jin, 2007; Xue, 2008) and airline networks (Yu et al., 2008).

\section{Prospects for future research}

\subsection{Spatial optimization of the transport network}

Studies during all periods have been related to the development level of the economy and to research objectives. During the last 100 years, the transport infrastructure, including railways, highways, ports, and airports, has formed a complete and integrated network in physical space. From the scale and the spatial coverage of the transport network, it can be seen that transportation has finished its period of skeleton construction and network expansion and entered a period of generalization and upgrading, especially in the cases of rail and road transport. Transportation and socio-economic development are gradually becoming increasingly coordinated under the influence of the rapid development of transportation and economy in China. Currently, transportation in China can satisfy the basic demands of socio-economic development, and the relationship between transportation and economy is in the coordinated development stage at a national level, but the coordination between trans- 
portation and economy is uneven at provincial and city levels. With increasing demand for temporal effectiveness of socio-economic development, the state of development of transportation could change from one network expansion to one in which the existing network is upgraded and an optimum combination of different transport modes is achieved. As a result, studies on cooperation and competition among transport modes and on spatial optimization of transportation will be of great significance in the future. Some researchers have examined the spatial optimization and configuration of transportation by exploring the impacts of a speed-up campaign on the railways, the restructuring of airlines, and the development of HSR and expressways.

\subsection{Influences of transport construction and expansion on regional development}

The interdependence of the transport network and regional development is still a hot topic of research for transport geographers. As a basic component of regional structure and a basic supporting condition for regional development, the transport network is significant in guiding and optimizing the spatial order of regional development. An important aim for future work is to explore the spatial distribution, spatial organization, and relationship of transport infrastructure and regional development. On the basis of previous studies, researchers should pay close attention to the following aspects: the general relationship between transportation and regional development, the specific relationship between transportation and territorial development, and the coupling and coordinating relationship between transportation and the evolution of the socio-economic system. The most important questions concern the basic modes and mechanisms of cost-space convergence, time-space convergence, cost convergence-flow expansion, and spatial coupling and coordination. Studies in these areas can serve as an important guide supporting future regional development in China.

\subsection{Socio-environmental effects of integrated transport infrastructure}

The construction and development of transport infrastructure has a strong influence on the natural, socio-economic, and environmental bases of regional development. In view of this, the aim of exploring the impact of an integrated transport infrastructure is to reveal the effects and the underlying mechanisms of nature-human-society-environment interactions and to develop methods for evaluating the relationships between transportation and regional development, as well as methods to adjust and optimize these. To better understand the impact of an integrated transport network, researchers should pay much closer attention to the following aspects in the future: the relationship between transportation and urbanization, the coupling and coordinating relationship between regional development and the socio-economic and environmental impacts of expressway networks, and the socio-environmental impact of infrastructure on urban agglomerations. Research in this area should be able to reveal the role of the transport network in complex regional nature-human systems from different perspectives, to determine the relationship between transportation and regional development, and to provide a basis for discussing possible approaches to adjusting and optimizing the relationship between the infrastructure network and regional development. This area of study has important scientific value in supporting regional development and the construction of the infrastructure network in China. 


\subsection{Spatial organization of spatial flow and its influence on the socio-economic system}

The spatial and economic impacts of improvements in transportation and communication technology and networks are important topics of study from a geographical perspective, with the aim of enriching the theory of spatial economic location and industrial spatial organization, exploring the mechanisms of spatial interaction and the evolution of spatial flows (e.g., of logistics, people, information, and energy), and identifying scientific parameters with universal significance. Such studies can provide scientific support for regional, metropolitan, and ecological planning, etc. Research priorities in this area include the relationship between spatial flow and spatial logistics systems on the one hand and technological progress in transportation and communication on the other, as well as the interactions between e-commerce and the transportation and communication infrastructure.

\subsection{Metropolitan transport network and its spatial organization}

Large-scale and high-speed urbanization is currently the main trend of China's socio-econoic development. All kinds of urban-intensive areas have become the main form of future urbanization in China. In the development of a transportation infrastructure, many regions have constructed similar traffic facilities (e.g. airports and ports), which has led to unnecessary repetition in construction and a waste of resources. Meanwhile, although the transport networks of mega-cities are continuing to improve, traffic is becoming more and more congested, with serious adverse effects on the development of cities and the productivity and lives of their residents. The phenomena of repetitive infrastructure construction and traffic congestion are prominent in the developed urban-intensive areas, such as the Pearl River Delta, the Yangtze River Delta and the Beijing-Tianjin-Hebei metropolitan region. Therefore, geographers have started to pay attention to research on transport systems in urban-intensive areas and mega-cities. They are exploring the construction of transport systems and modes of organization of transport networks in these areas, to reveal the mechanism of interaction among transport infrastructure networks, transport organization networks, and the socio-economic spatial structure of urban areas. Such studies now form the frontier of transportation geography.

\section{References}

Cao Xiaoshu, Xue Desheng, Yan Xiaopei, 2005. A study on the urban accessibility of the national trunk highway system in China. Acta Geographica Sinica, 60(6): 903-910. (in Chinese)

Cao Xiaoshu, Yan Xiaopei, 2006. Spatial Evolution of the Guangzhou-Shenzhen-Hong Kong Transport Corridor. Beijing: The Commercial Press. (in Chinese)

Cao Youhui, 1999. On the spatial structure of the Changjiang River port system. Acta Geographica Sinica, 54(3): 233-240. (in Chinese)

Cao Youhui, Cao Weidong, Jin Shisheng et al., 2003. The evolution mechanism of the coastal container port system of China. Acta Geographica Sinica, 58(3): 424-432. (in Chinese)

Cao Youhui, Li Haijian, Chen Wen, 2004. The spatial structure and competition pattern of the container port system of China. Acta Geographica Sinica, 59(6): 1020-1027. (in Chinese)

Chen Hang, 1984. The economic geographic basis of seaport development and distribution. Scientia Geographica Sinica, 4(2): 125-131. (in Chinese) 
Chen Hang, 1991. Preliminary studies of areal combination and division of ports in the coastline area. Acta Geographica Sinica, 46(4): 480-487. (in Chinese)

Chen Hang, 1996. On the formation and evolution of seaport regional complexes. Acta Geographica Sinica, 51(6): 501-507. (in Chinese)

Chen Hang, Zhang Wenchang, Jin Fengjun, 1993. Transportation Geography of China. Beijing: Science Press. (in Chinese)

Chen Hang, Zhang Wenchang, Jin Fengjun et al., 2000. Transportation Geography of China. Beijing: Science Press. (in Chinese)

Dai Teqi, Zhang Yuhan, Wang Jiaoe et al., 2014. Population coverage evaluation of civil airports in China based on optimization models. Geographical Research, 33(4): 710-720. (in Chinese)

Geng Dading, Chen Chuankang, Yang Wuyang et al., 1978. On the highway natural regionalization of China. Acta Geographica Sinica, 33(1): 49-62. (in Chinese)

Giuliano G, 2001. Transportation geography. International Encyclopedia of the Social and Behavioral Sciences, 10(4): 15866-15873.

Givoni M, 2015. Transport and transportation geography in Israel: In-between "local" and "international". Journal of Transport Geography, 49: 112-113.

Hall D, 2010. Transportation geography and new European realities: A critique. Journal of Transport Geography, 18: 1-13.

Han Zenglin, An Xupeng, Wang Li et al., 2008. Distribution and optimization of the container transportation network in China. Acta Geographica Sinica, 57(4): 479-488. (in Chinese)

Huang Shengzhang, 1957. The development of transport in Sichuan and Shaanxi provinces. Acta Geographica Sinica, 23(4): 419-435. (in Chinese)

Jiang Haibing, Xu Jiangang, Qi Yi, 2010. The influence of the Beijing-Shanghai high-speed railway on land accessibility of regional center cities. Acta Geographica Sinica, 65(10): 1287-1298. (in Chinese)

Jiao J, Wang J, Jin F et al., 2014. Impacts on accessibility of China's present and future HSR network. Journal of Transport Geography, 40: 123-132.

Jiao Jingjuan, Wang Jiaoe, Jin Fengjun et al., 2016. Impact of high-speed rail on an inter-city network based on the passenger train network in China, 2003-2013. Acta Geographica Sinica, 71(2): 265-280. (in Chinese)

Jin Fengjun, 2001. A study on the network of domestic air passenger flow in China. Geographical Research, 20(1): 31-39. (in Chinese)

Jin Fengjun, 2004. Infrastructure system and regional development. China Population, Resources and Environment, 14(4): 70-74. (in Chinese)

Jin Fengjun, 2013. Infrastructure System and Socio-economic Spatial Organization. Beijing: Science Press. (in Chinese)

Jin Fengjun, Wang Chengjin, 2005. Hub and spoke system and organization of the China aviation network. Geographical Research, 24(5): 774-784. (in Chinese)

Jin Fengjun, Wang Chengjin, Li Xiuwei, 2008. Discrimination method and its application to analysis of regional transport superiority. Acta Geographica Sinica, 63(8): 787-798. (in Chinese)

Jin Fengjun, Wang Chengjin, Li Xiuwei et al., 2010. China's regional transport dominance: Density, proximity, and accessibility. Journal of Geographical Sciences, 20(2): 295-309.

Jin F, Wang F, Liu Y, 2004. Geographic patterns of air passenger transport in China: 1990-1998: Imprints of economic growth regional inequality and network development. The Professional Geographer, 56(4): 471-487.

Jin Fengjun, Wang Jiaoe, 2004. Railway network expansion and spatial accessibility analysis in China: 1906-2000. Acta Geographica Sinica, 59(2): 293-302. (in Chinese)

Keeling D J, 2015. Transportation geography in Peru. Journal of Transport Geography, 46: 253-255.

Koichi T, 2014. Transport geography in Japan. Journal of Transport Geography, 34: 305-306.

Liu Chengliang, Xu Ruilin, Xiong Jianping et al., 2009. Spatial accessibility of the road network in the Wuhan Metropolitan Area. Acta Geographica Sinica, 64(12): 1488-1498. (in Chinese)

Mo Huihui, Wang Jiaoe, 2012. Complex Transport Network: Structure, Progress and Mechanism. Beijing: Econ- 
omy and Management Publishing House. (in Chinese)

Okada H, 1994. Features and economic and social effects of the Shinkansen. Japan Railway and Transport Review, 33: 9-16.

Rong Chaohe, 1995. A macro effect of transportation on changes in economic spatial structure. Acta Geographica Sinica, 50(5): 394-401. (in Chinese)

Shen Yuchang, 1952. The terrain and transport construction between Sichuan and Guizhou. Acta Geographica Sinica, 18(3/4): 136-147. (in Chinese)

Sheng Xugong, 1931. Transportation Geography. Beijing: China Commerce and Trade Press. (in Chinese)

Taaffe E J, Gauthier H L, 1994. Transportation geography and geographic thought in the United States: An overview. Journal of Transport Geography, 2(3): 155-168.

Wang Boli, Zhang Xiaolei, 2010. The contribution of highway traffic infrastructure construction to economic growth in Xinjiang based on I-O and ESDA. Acta Geographica Sinica, 65(12): 1522-1533. (in Chinese)

Wang Chengjin, 2007. Evolution and mechanism of development of the port distribution system in China. Acta Geographica Sinica, 62(8): 809-820. (in Chinese)

Wang Chengjin, 2008. Spatial organization networks of world marine container transportation. Geographical Research, 27(3): 636-648. (in Chinese)

Wang Chengjin, Ding Jinxue, Yang Wei, 2011. Policy and spatial effect of an expressway planning network in China. Acta Geographica Sinica, 66(8): 1076-1088. (in Chinese)

Wang Chengjin, 2012. Evolution and Mechanism of Development of a Container Port System. Beijing: Science Press. (in Chinese)

Wang Chengjin, 2014. Spatial Organization Mode and Mechanism of Logistic Enterprises. Beijing: Science Press. (in Chinese)

Wang Chengjin, Wang Wei, Zhang Mengtian et al., 2014. Evolution, accessibility of road networks in China and dynamics: from a long perspective. Acta Geographica Sinica, 69(10): 1496-1509. (in Chinese)

Wang Derong, Cai Bencheng, 1986. China Transportation Distribution. Beijing: Science Press. (in Chinese)

Wang Jiaoe, Jiao Jingjuan, Du Chao et al., 2015. Competition of spatial service hinterlands between high-speed rail and air transport in China: Present and future trends. Journal of Geographical Sciences, 25(9): 1137-1152.

Wang Jiaoe, Jin Fengjun, 2005. Railway network organization and spatial service system optimization in China. Acta Geographica Sinica, 60(3): 371-380. (in Chinese)

Wang Jiaoe, Jin Fengjun, Sun Wei et al., 2006. Research on the spatial distribution and service level of the Chinese airport system. Acta Geographica Sinica, 61(8): 829-838. (in Chinese)

Wang J, Jin F, 2007. China's air passenger transport: An analysis of recent trends. Eurasian Geography and Economics, 48: 469-480.

Wang J, Jin F, Mo H et al., 2009a. Spatiotemporal evolution of China's railway network in the 20th century: An accessibility approach. Transportation Research Part A: Policy and Practice, 43(8): 765-778.

Wang Jiaoe, Mo Huihui, 2009. Discussion on the distribution of civil airports. Journal of Civil Aviation Flight University of China, 20(6): 7-10. (in Chinese)

Wang J, Mo H, Wang F, 2014. Evolution of air transport network of China 1930-2012. Journal of Transport Geography, 30: 145-158.

Wang J, Mo H, Wang F et al., 2011. Exploring the network structure and nodal centrality of China's air transport network: A complex network approach. Journal of Transport Geography, 11: 712-721.

Wang Jiaoe, Mo Huihui, Jin Fengjun, 2009b. Spatial structural characteristics of the Chinese aviation network based on complex network theory. Acta Geographica Sinica, 64(8): 899-910. (in Chinese)

Wu Chuanjun, Gao Xiaozhen, 1989. A model of port-city development. Geographical Research, 8(4): 9-15. (in Chinese)

Wu Chuanjun, Sun Chenglie, Deng Jingzhong, 1955. Preliminary experience of survey methods on the selection of rail lines. Acta Geographica Sinica, 21(2): 155-164. (in Chinese)

Wu Miao, Yang Zhaoping, Dai Songying, 2009. Analysis on Russia socio-economic geography development since 1990s. World Regional Studies, 18(1): 157-164. (in Chinese) 
Wu Qitao, Zhang Hongou, Chen Fenggui et al., 2010. The hub and spoke network and its application in transportation geography. Progress in Geography, 29(6): 701-708. (in Chinese)

Wu Wei, Cao Youhui, Cao Weidong et al., 2006. Spatial structure and evolution of highway accessibility in the Yangtze River Delta. Acta Geographica Sinica, 61(10): 1065-1074. (in Chinese)

Wu Wei, Cao Youhui, Liang Shuangbo et al., 2009. The accessibility pattern of the railway passenger transport network in China. Geographical Research, 28(5): 1389-1400. (in Chinese)

Xiu Chunliang, Zhao Yinghui, Song Wei, 2008. Spatial polarization of railway transport in northeast China: 1990-2005. Acta Geographica Sinica, 63(10): 1097-1107. (in Chinese)

Xu Gang, 1990. The function, pattern and development of the lower Changjiang River ports system in Jiangsu province. Acta Geographica Sinica, 45(3): 275-283. (in Chinese)

Xue Junfei, 2008. Hierarchical structure and distribution pattern of the Chinese urban system based on the aviation network. Geographical Research, 27(1): 23-31. (in Chinese)

Yang Wuyang, 1964. Regionalization and natural condition of land transport in China. Acta Geographica Sinica, 30(4): 301-319. (in Chinese)

Yang Wuyang, Zhang Guowu, Zhang Wenchang et al., 1986. Transportation Geography. Beijing: China Commerce and Trade Press. (in Chinese)

Ye Shunzan, 1998. The areas along the newly constructed Beijing-Kowloon Railway. Acta Geographica Sinica, 53(2): 157-165. (in Chinese)

Yu Taofang, Gu Chaolin, Li Zhigang, 2008. China's urban systems in terms of air passenger and cargo flows since 1995. Geographical Research, 27(6): 1407-1418. (in Chinese)

Zhang Bing, 2007. Regional effect study of rapid land transportation [D]. Beijing: Institute of Geographic Sciences and Natural Resources Research, Chinese Academy of Sciences. (in Chinese)

Zhang Guowu, 1965. Introduction to Chinese Economic Geography: Transportation Geography. Beijing: Science Press. (in Chinese)

Zhang Qian, Hu Yunfeng, Liu Jiyuan et al., 2011. Identification of urban clusters in China based on assessment of transportation accessibility and socio-economic indicators. Acta Geographica Sinica, 66(6): 761-770. (in Chinese)

Zhang Wenchang, Jin Fengjun, Fan Jie, 2000. Traffic Economic Belts. Beijing: Science Press.

Zhang Wenchang, Jin Fengjun, Rong Chaohe et al., 1993. Spatial Transportation Linkage: Theoretical Study, Experimental Analysis and Forecasting Methods. Beijing: China Railway Publishing House. (in Chinese)

Zhang Wenchang, Jin Fengjun, Tang Xiufang, 1994a. The formation and growth regularities of spatial transport linkage. Acta Geographica Sinica, 49(5): 440-448. (in Chinese)

Zhang Wenchang, Jin Fengjun, Tang Xiufang, 1994b. Distribution and exchange regularities of spatial transport linkage. Acta Geographica Sinica, 49(5): 490-499. (in Chinese)

Zhang Wudong, 1993. Transportation Distribution. Shanghai: East China Normal University Press. (in Chinese)

Zhou Yixing, Hu Zhiyong, 2002. Looking into the network structure of the Chinese urban system from the perspective of air transportation. Geographical Research, 21(3): 276-286. (in Chinese) 